lhoria da qualidade de vida na comunidade, evitando ou postergando a internação em instituições de longa permanência para idosos.

\title{
Projeto Acompanhamento de Idosos
}

Marília Anselmo Viana da Silva Berzins, Sérgio Márcio Pacheco Paschoal, Maria Celina Rangel de Andrade, Sandra Sheila Santos Patto, Maria de Jesus Batista Mendes Iannarelli*, Rosângela Ogawa**

Prefeitura da Cidade de São Paulo. Secretaria de Saúde. E-mail: mariliaa@prefeitura.sp.gov.br

*Centro Social Nossa Senhora do Bom Parto. Assistência Social.

E-mail: mariaiannarelli@argentina.com

*Associação Saúde da Família. Saúde Mental.

Endereço: Praça Marechal Cordeiro de Farias, 65, Higienópolis, CEP 01244-050, São Paulo, SP, Brasil.

E-mail: rogawa@saudedafamilia.org

O envelhecimento da população humana mundial e brasileira foi um dos maiores triunfos da humanidade no último século. Viver mais é uma conquista que se associa a um grande desafio: viver com dignidade e qualidade. Esse desafio requer o compromisso da família, da sociedade civil e do estado na oferta de respostas eficientes para suprir as necessidades da população idosa, advindas com o acréscimo dos anos à existência humana. 0 Projeto Acompanhamento de Idosos é uma política pública desenvolvida na cidade de São Paulo pela Secretaria Municipal da Saúde em parceria com a Associação Saúde da Família e o Centro Social Nossa Senhora do Bom Parto. O Projeto atende pessoas idosas em situação de fragilidade, que possuem limitações nas atividades da vida diária. Para atendê-las, são contratadas profissionais denominadas “Acompanhantes de Idosos", que prestam serviços nos domicílios oferecendo auxílios distintos para a me- 